\title{
A Festschrift to Professor E C Subbarao on the occasion of his 90th Birthday
}

\author{
Pradip $^{1} \cdot$ Himanshu Jain ${ }^{2} \cdot$ Himadri S. Maiti ${ }^{3}$
}

Published online: 5 July 2019

(C) The Indian Institute of Metals - IIM 2019

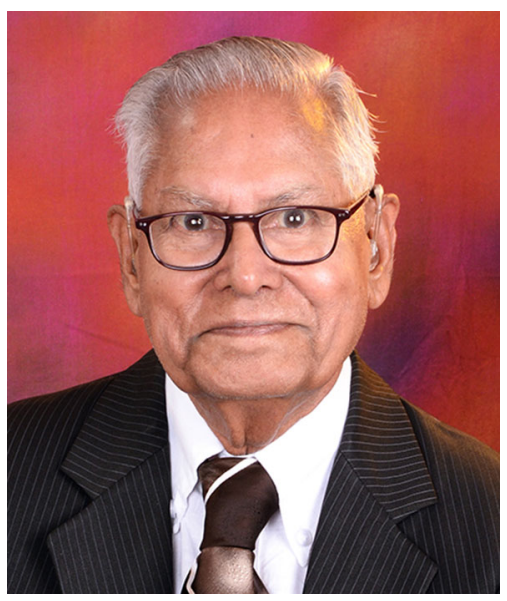

This special issue of the Transaction of IIM commemorates the numerous contributions made by Professor E. C. Subbarao to India's scientific and technological development over half a century. Published on the occasion of his 90th birthday, the festschrift consists of 25 papers contributed by his former colleagues, associates and students, covering

Pradip

pradip18568@gmail.com

Himanshu Jain

h.jain@lehigh.edu

Himadri S. Maiti

hsmaiti2009@gmail.com

1 Tata Consultancy Services Ltd (TCS), Tata Research Development and Design Centre (A Division of TCS), Hadapsar, Pune, India

2 Institute for Functional Materials and Devices (I-FMD), Lehigh University, Bethlehem, PA, USA

3 Govt College of Engineering and Ceramic Technology, Kolkata, India

several challenging areas of contemporary research interest and value to minerals, metals and materials community.

Born on August 8, 1928, in Narsapur, Andhra Pradesh, India, Professor Subbarao graduated from Banaras Hindu University with B.Sc. in Glass Technology in 1949. He then earned B.S. in 1952 and M.S. in 1953 in Ceramic Engineering from University of Washington, followed by a Ph.D. from Pennsylvania State University in 1957. Upon graduation, he joined Westinghouse Research Laboratories in Pittsburgh, where he conducted materials research for 7 years (1956-1963). He then returned to India to become the first Head of the Department of Metallurgical Engineering, and subsequently as the Dean of Faculties at Indian Institute of Technology, Kanpur (IITK).

In 1980, Prof. Subbarao was invited by the Tata Group to help establish and build a new iconic institution in the country, named Tata Research Development and Design Centre (TRDDC) in Pune, with the goal of applying existing knowledge for the benefit of industry and people. It was established in 1981 under his leadership, where he nurtured multidisciplinary research groups, to solve some of the most challenging problems facing the Indian industry and to develop novel model-based solutions, covering the whole value chain, starting from design, prototyping, scale-up and implementation on the shop floor to process optimization and control in the running plants. He helped build successful, synergistic collaboration at TRDDC between diverse engineering groups, specifically the software engineering group and the minerals, metals and materials engineering group, working under one roof and learning from each other's strengths and experiences.

Prof. Subbarao is considered the father of materials science education in India. He organized the First Materials Science Education Conference in India at IITK, with wide participation from academia, research institutions and industries, as well as three professors from the USA. He 
established the first interdisciplinary graduate program in Materials Science in India at IITK. He served Indian academia, in various capacities and helped institutionalize the very best in engineering education, research and industryacademia partnership. His book "An Eye for ExcellenceFifty Innovative Years of IITK" (Harper Collins, 2008) presents his perspectives and chronicles the efforts made by the pioneers at IITK.

With more than 200 research publications and ten books either co-edited or co-authored, Prof. Subbarao made pioneering contributions to advanced materials research including ferroelectric materials and devices, solid electrolytes and their industrial applications and rare-earth magnets. He has served on the editorial boards of several prestigious international journals including Bulletin of Materials Science, Ferroelectrics, Ceramics International, Condensed Matter News, Journal of Materials Synthesis and Processing, International Journal of Materials and Product Technology and Transactions of Indian Ceramic Society.

He has contributed significantly to the advancement of science and technology enterprise in India during its formative years after the Independence through service to several high-level national policy committees. To name a few, he has served on the First Science \& Engineering Research Council of the Department of Science and Technology (1974-1977), the Technology Development Council of the Department of Electronics (1972-1980), the First Indo-US Sub-Commission on Science and Technology and the Atomic Energy Regulatory Board.

Prof. Subbarao is the recipient of several prestigious awards and honours during his illustrious professional career of more than 6 decades. He has been honoured with the Fellowship of various science and engineering academies-Indian Academy of Sciences, Indian National Science Academy (INSA), Indian National Academy of Engineering, the Indian Institute of Ceramics and the Founder Member of the International Academy of Ceramics (1990). He is the recipient of Homi Bhabha Award in Applied Science (1978), MRSI Distinguished Materials Scientist of the Year (1991), INSA Award in Materials Science (1995), BHU Distinguished Alumnus Award (1998), Honorary Member of the Indian Institute of Metals and the First Honorary Fellow of IIT Kanpur (2006), to name a few.

Professor Subbarao has mentored several professionals, who went on to become highly successful faculty members and industry leaders. On behalf of all his students, colleagues, well-wishers and friends all over the world, we wish him many more years of good health and enjoyable life ahead. On a personal note, all three of us also happen to be his students and we would like to express our sincere gratitude for his extraordinary mentorship.

We thank all the contributors to this special issue who have very kindly accepted our invitation and tried their best to meet the publication deadlines. The valuable advice and timely assistance provided by Professor B. S. Murty, Chief Editor, and Dr. R. Sandhya, Editorial Manager, throughout the editing of this issue are gratefully acknowledged. Pradip acknowledges the kind help, encouragement and support provided by Mr. K. Ananth Krishnan, Executive Vice President and the Chief Technology Officer, Tata Consultancy Services, in this effort.

Publisher's Note Springer Nature remains neutral with regard to jurisdictional claims in publishedmaps and institutional affiliations. 